\title{
Prevalence of Reproductive Tract Infections/ Sexually Transmitted Infections among Women in a Tertiary Care Hospital- An Observational Study
}

\author{
RubyBhatia ${ }^{1}$, Parmjit Kaur ${ }^{2}$, Santosh Kumari ${ }^{3}$, Aman Dev ${ }^{4}$ \\ ${ }^{I}$ MBBS, MD OBG, FICOG, Associate Professor, Deptt of Obstetrics and Gynaecology, Govt Medical College \\ and Rajindera Hospital, Patiala, Punjab. \\ ${ }^{2}$ MBBS, MD OBG,FICOG, Professor, Deptt of Obstetrics and Gynaecology, Govt Medical College and \\ Rajindera Hospital, Patiala, Punjab. \\ ${ }^{3}$ MBBS, Postgraduate student, Deptt of Obstetrics and Gynaecology, Govt Medical College and Rajindera \\ Hospital, Patiala, Punjab. \\ ${ }^{4}$ MBBS, MD PSM, Medical College and Rajindera Hospital, Patiala, MO Civil Surgeon Office Patiala.
}

\begin{abstract}
Background: Reproductive tract infections (RTIs) /sexually transmitted infections (STIs) are an important public health problem: 6\% of adult population in India has one or more RTI/STI. Approximately 30-35 million new episodes of RTI/STI occur every year in country. RTI/STI are an important cause of infertility. Roughly $21 \%$ pregnancies result in still birth and $9 \%$ in neonatal death due to untreated syphilis.

Aims and Objectives: To study the prevalence of RTI/STI in women, to find out commonest RTI/STI and its correlation with HIV/VDRL and Pap Smear abnormality if any.

Material \& Methods: This is a cross-sectional observational study undertaken for one year in 2294 consecutive women with RTI/STI in the age group of 15-49 years, attending the Gynaecology outpatient Department of a tertiary-care hospital in North India

Result: The prevalence of RTI/STI in our study was 13.19\%. Majority of patients were married (94.86\%), Para 1 and above (93.4\%) from low socio economic group (90.6\%), illiterate (72.5\%) between 26-35 years of age (67.47\%). Vaginal discharge (62.51\%) and lower abdominal pain / backache (43.42\%) were most common presenting complaints. Vaginitis (62.51\%), cervicitis (27.81\%) and chronic pelvic inflammatory disease (PID) (15.63\%) were most frequently encountered RTI/STI. Bacterial vaginosis (49.79\%), candidiasis (35.84\%) and trichomoniasis (21.33\%) were important causes of vaginal discharge either alone or in combination. HIV and VDRL were reactive in only $15(0.68 \%)$ and $11(0.56 \%)$ RTI/STI females respectively. Inflammatory Pap smear was observed in $36.4 \%$ cases while nine cases $(0.9 \%)$ had cervical dysplasia of varying degree.

Conclusion: Vaginal discharge and lower abdominal pain are the commonest presenting complaints. Mixed vaginitis, cervicitis and chronic PID are frequently encountered RTI/STI in Gynae OPD practice. Bacterial vaginosis, candidiasis and Trichomoniasis remain important causes of vaginal discharge. Counselling, testing for HIV/VDRL and pap smear analysis alongwith syndromic management helps in prevention of RTI/STI.
\end{abstract}

Keywords: Reproductive tract infections, Sexually transmitted infections, Vaginal discharge, Condom.

\section{Introduction}

Sexually transmitted infections (STIs) / Reproduction tract Infections (RTIs) are an important public health problem in developing world and rank in the top five disease categories for which adult seek health care. They are silent epidemic for women of reproductive age group in developing countries. ${ }^{[1]}$ RTIs are defined as any infection of the reproductive system. They include STIs and also other infections of the reproductive system that are not caused by sexual contact. STIs are infections transmitted from person to person by sexual contact ${ }^{[2]}$. Globally 499 million new episodes of sexually transmitted infections (trichomoniasis, Chlamydia, gonorrhoea, syphilis) occur yearly in the age group 15-49 years of which a significant proportion (80\%) of these infections occur in developing countries and 79 million in India alone. ${ }^{[3]}$ Women are more susceptible to STIs for socioeconomic and biological reasons. The vaginal surface is larger and more vulnerable to sexual secretions than primarily skin covered penis.

$11 \%$ women and $5 \%$ men in $15-49$ years age group have RTI/STI related symptoms ${ }^{[4]}$. STI/RTI are known to cause infertility and reproductive morbidity affecting not only mother but also new born adversely. STIs have been associated with number of adverse pregnancy outcomes: spontaneous abortion, still birth, prematurity, low birth weight, postpartum endometritis and sequlae in surviving neonates. With the recognition of human immunodeficiency virus (HIV) infection in 1980s and subsequent behaviour, social and psychological changes, the pattern of genital ulcer disease has shifted from bacterial to viral STIs. ${ }^{[5]}$. There is significant 
decline of bacterial STIs (Syphilis and gonorrhoea). Chancroid is on verge of disappearance while viral STIs are showing an increasing trend. STIs are markers for high risk behaviour for HIV infection. STIs are biological cofactors for acquisition and transmission of HIV infection. ${ }^{[6]}$

\section{Materials \& Methods}

It was an observational study conducted in outpatient department of Obstetric Gynaecology (STI clinic) Government Medical College, Patiala for a period of one year (1-9-2009 to 31-8-2010) on a total of 2294 RTI/STI female patients in the age group of 15-49 years, with an aim to study the prevalence of RTI/STI, to find out commonest RTI/STI and its correlation with HIV, VDRL and Pap smear abnormality, if any. A detailed history with special reference to any abnormal vaginal discharge amount, colour, odour, rash or pruritis over genitalia, frequency / burning micturition, pain lower abdomen / backache, dysmenorrhoea, post coital bleeding, menorrhagia, infertility. History of high risk sexual behaviour (oral / anal sex), number of sexual partners. Gynaecological examination including per speculum and per vaginum examination undertaken with complete audio visual privacy. Women with carcinoma cervix were excluded from study. All patients with RTI/STI referred to ICTC centre for voluntary counseling and testing for HIV antibody test and VDRL/RPR for syphilis. Wet mount, $10 \% \mathrm{KOH}$, Whiff test, and gram stain of the vaginal discharge and Pap smear with Ayre's spatula was made in all cases. All RTI/STI patients were treated as per user friendly syndromic approach to management with color coded kits, partner management and provision of condoms, counselling for safe sex with correct and consistent use of condoms done in all cases.

\section{Results}

With a total outpatient attendance of 17,392 for one year study period, 2294 females were diagnosed suffering from various RTIs/STIs. Overall prevalence of RTI/STI was $13.91 \%$. $15(0.68 \%)$ patients were positive for HIV Antibody Test while VDRL/RPR was reactive in $11(0.56 \%)$ RTI/STI cases (Table 1). Majority of RTI/STI females were married (94.86\%), > Para one and above (93.36\%), in 26-35 years of age (67.47\%), from low and low middle socio-economic group (90.68\%) and $72.5 \%$ were illiterate (Table 2). $62.51 \%$ RTI/STI women presented with vaginal discharge followed by $43.42 \%$ with lower abdominal pain and backache. Prurites vulvi, dysparunia, dysmenorrhoea, polymenorrhagia, dysuria, postcoital bleeding and anorectal discharge were other presenting complaints (Table 3). Majority of patients had more than one complaint. A diagnosis of vaginitis mostly mixed vaginitis made in $62.51 \%$ RTI/STI women. Chronic cervicitis in 27.8 and chronic pelvic inflammatory disease in $15.63 \%$ followed by urethritis in $4.18 \%$ and syphilis in $0.48 \%$ (Table 4). Many patients had vaginitis with cervicitis alongwith pelvic inflammatory disease. Bacterial vaginosis $(49.79 \%)$ was most important cause of vaginal discharge followed by candidiasis in $35.84 \%$ trichomoniasis in $21.33 \%$ and Bacterial (Neisseria Gonorrhoea) in $13.27 \%$ only (Table 5). Mixed Vaginitis due to more than one microorganisms was observed in many cases. Pap Smear cytology report of $996 \mathrm{RTI} / \mathrm{STI}$ patients were analysed. 36.4\% patient had inflammatory Pap Smear, six cases showed Koilocytosis while 9 women $(0.9 \%)$ had cervical dysplasia of varying degree (Table 6$)$.

\section{Discussion}

The prevalence of RTI / STI in our study group was 13.19\% National Family Health Survey III 2005 reports that $11 \%$ women and 5\% men in $15-49$ years age group have STI/RTI related symptoms ${ }^{[4]}$ almost similar to our results. The prevalence of RTI was $36.3 \%$ among women in reproductive age group in Shimla town ${ }^{[7]}$. Bohra et al. in their study observed 30\% of women had symptoms related to RTI and 19\% had STIs. Prevalence of RTI was estimated to be $27 \%$ among women by Hodge et $\mathrm{al}^{[9]} .0 .68 \%$ and $0.56 \%$ RTI/STI females in our study group were seropositive for HIV and syphilis respectively. Ray et al. (2009) reported low prevalence of HIV (0.1\%) among women with RTI/STI. Khokhar et al reported $0.49 \%$ positive for syphilis and $0.39 \%$ for $\mathrm{HIV}^{[12]}$. Majority of patients were married $(94.86 \%)$, Para 1 and above $(93.36 \%)$ illiterate $(72.5 \%)$ from low socio economic status. Similar results were reported by Ray et al. ${ }^{[10]}$ Majority of our patients $(67.47 \%)$ were in the age group of 26-35 years as observed by Jindal et al \& Gupta ${ }^{[12,13]}$. Vaginal discharge $(62.51 \%)$ was the most common presenting complaint in present study. We reported vaginal discharge in $80 \%$ HIV negative and $66 \%$ in HIV positive. RTI/STI females in our previous study ${ }^{[14]}$. Vaginal discharge $(62.51 \%)$ and lower abdominal pain / backache were the most common symptoms in our study in accordance with other authors ${ }^{[9,12,13]}$. Majority of patients in our study had vaginitis $(62.51 \%)$, followed by cervicitis in $27.81 \%$ and pelvic inflammatory disease in $15.63 \%$. Thus kit-1, kit-2 and kit-6 were utilized to the maximum. The most common cause of vaginitis was observed to be bacterial vaginosis (49.79\%) followed by candidiasis in $35.84 \%$ and trichomonal in $21.33 \%$ while bacterial (gonorrhoea) in $13.27 \%$ only. Many of patients had mixed vaginitis. There is significant burden of lower RTI (trichomoniasis, bacterial vaginosis and candidiasis) among women with no evidence to suggest a decline in prevalence, thus affecting quality of their reproductive life ${ }^{[3]}$. In our previous study also we observed 
that in case of HIV negative women, the most common cause of vaginal discharge was bacterial vaginosis (28\%) followed by candidiasis (22\%), trichomoniasis $18 \%$ and gonorrhoea in $2 \% .^{[14]}$

$36.4 \%$ RTI/STI females had inflammatory Pap Smear while $9(0.9 \%)$ had cervical dysplasia of varying degree in our study. Pap smear were inflammatory in 56\% and $22 \%$ in HIV positive and HIV negative STI/RTI women respectively as reported in our previous study. ${ }^{[14]}$ Seethalakshmi et al reported abnormal Pap smear in $58.8 \%$ and $43.75 \%$. HIV positive and HIV negative women respectively. ${ }^{[15]}$ In a study conducted by Sharma et al inflammatory smears were seen in 55\% and $28 \%$ while cervical dysplasia was reported in 5\% and 3\% HIV positive and HIV negative STI/RTI patients respectively. ${ }^{[16]}$

\section{Conclusion}

Prevalence of RTI/STI in our Gynaecology outpatient department, a tertiary Care Hospital was reported to be $13.19 \%$ in women of reproductive group. Vaginitis, cervicites and pelvic inflammatory disease are commonly encountered RTI/STI. There is significant burden of lower RTI (Bacterial vaginosis, candidiasis and trichomoniasis) among women with no evidence to suggest a decline in prevalence. Counselling and testing for HIV/VDRL and pap smear alongwith user friendly Syndromic Approach may go a long way in management of RTI/STI.

\section{References}

[1]. Elahee SMA, Muhmud S, Tanvir S, Rahman MZ, Breaking the silence : reproductive tract infections (RTIs) among women in slums of Khulna City, Bangladesh, Bangladesh, e-Journal of Sociology 2013; 10(2) : 119-34.

[2]. Sharma VK, Khanpur S. Epidemiology of Sexually transmitted diseases. In : Sharma VK, editor Sexually transmitted Diseases and AIDS, New Delhi : Viva Books Pvt. Ltd., 2003, p.11-2.

[3]. National Guidelines on Prevention Management and Control of Reproduction Tract Infections and Sexually Transmitted Infections, July 2014.

[4]. National Family Health Survey III 2005-2006, Ministry of Health \& Family Welfare, Government of India.

[5]. Sharma VK and Khandpur S. Changing patterns of Sexually transmitted infections in India, Natl Med J India 2004; 17(6) : 310-9.

[6]. Fact Sheet : Sexually transmitted infections (internet) World Health Organisation, 2011 Aug. Available from : http://www.who.int/mediacentre/factsheets/FS/10/en/

[7]. Prashar A, Gupta BP, Bhardwaj AK, Sarin R, prevalence of RTIs among women of reproductive age group in Shimla town. Indian J Community Med. 2006, 31 : 15-7.

[8]. Bohra MS, Joshi AB, Lekhak B, Gurung G. Reproductive Tract Infections among women attending gynaecology outpatient department. Int J. Infect Microbiol $2012: 1(1): 29-33$.

[9]. Hedge SKB, Aggarwal T, Ramesh N, Sugara M, Joseph PM, Singh S, Thimmaiah S. Reproductive tract infections among women in a periurban under privileged area in Bangalore, India : Knowledge, prevalence and treatment seeking behaviour. Ann Trop Med Public Health 2013; $6: 215-20$.

[10]. Ray K, Muralidhar S, Bala M, Kumari M, Salhan S., Gupta SM et al. Comparative study of syndromic and etiological diagnosis of reproductive tract infections / sexually transmitted infections in women in Delhi Int J. Infect Dis. 2009; 13(6) : 352-9.

[11]. Khokhar N, Jethwa D, Lunagaria R, Panchal N, Badrakiya S, Badrakiya G. Seroprevlaence of Hepatitis B, Hepatitis C, Syphilis and HIV in pregnant women in a Tertiary Care Hospital, Gujarat India Int. J. Curr. Microbiol, App. Sci 2015; 4(9) : 188-94.

[12]. Jindal N, Aggarwal A, Gill P, Sabharwal B, Sheevani BB Community based study of Reproductive Tract Infections including sexually transmitted infections, among the rural population of Punjab, India, Indian J. Community Med. 2009; 34(4) : 359-61.

[13]. Gupta A. Prevalence of STI/STDs among women of reproductive age group in Tribal district of North India, Sex Transm Infect 2013; 89: A 172

[14]. Chopra D, Sandhu I, Bahl RK, Bhatia R, Goyal A. Prevalence of Sexually transmitted infections in HIV positive and HIV negative females in a tertiary care hospital - An observational study. Indian J Sex Trans Dis 2015; 36 : 59-63.

[15]. Seethalakshmi GV, Shobha D, Mohan KR, Sourabh C, Manoharan G, Chandreshekhar C. A comparative study of Pap Smear findings among HIV positive and negative women at Government Hospital of Thoracic Medicine (GHTM) Tambaran BMJ Infect Dis $2012 ; 23: 35$.

[16]. Sharma A, Marfatia YS, Modi M. Reproductive tract infections in HIV positive women : A case control study : Indian J Sex Transma Dis 2009; $30: 16-8$.

Table 1: Distribution of OPD Gynae patients (1.9.2009 to 31.8.2010)

\begin{tabular}{|l|l|l|}
\hline & $\mathbf{N}$ & \%age \\
\hline Total OPD patients & 17,392 & 100 \\
\hline Total RTI/STI Females & 2294 & 13.19 \\
\hline RTI/STI patients with positive HIV Test & 15 & 0.68 \\
\hline RTI/STI patients with Reactive VDRL/RPR & 11 & 0.56 \\
\hline
\end{tabular}


Table 2: Sociodemographic characteristics (Total=2294/100\%)

\begin{tabular}{|l|l|l|l|}
\hline $\mathbf{1 .}$ & Age in years & $\mathbf{N}$ & $\mathbf{\%}$ \\
\hline & $<20$ & 123 & 5.36 \\
\hline & $21-25$ & 238 & 10.37 \\
\hline & $26-30$ & 912 & 39.75 \\
\hline & $36-40$ & 636 & 27.72 \\
\hline & $>41-49$ & 233 & 10.16 \\
\hline $\mathbf{2 .}$ & Marital Status & & \\
\hline & Married & 2176 & 94.86 \\
\hline & Unmarried & 9118 & 5.14 \\
\hline $\mathbf{3 .}$ & Parity & & \\
\hline & Nulliparous & 151 & 6.64 \\
\hline & $\geq$ Para 1 & 2143 & 93.36 \\
\hline 4. & Literacy & & \\
\hline & Illiterate & 1663 & 72.5 \\
\hline & Upto Class V & 353 & 15.4 \\
\hline & Class 6 X & 163 & 7.1 \\
\hline & $>$ Class X & 115 & 5.0 \\
\hline $\mathbf{5 .}$ & Socio-economic Group & & \\
\hline & Low & 1600 & 69.75 \\
\hline & Low Middle & 480 & 20.93 \\
\hline & Upper Middle & 214 & 9.30 \\
\hline & & & \\
\hline & & \\
\hline & & \\
\hline
\end{tabular}

Table 3:Distribution as per Presenting complaints (Total $=2294 / 100 \%)$

\begin{tabular}{|l|l|l|}
\hline Presenting Complaints & Number & \%age \\
\hline Vaginal Discharge & 1434 & 62.51 \\
\hline Lower abdominal pain \& backache & 996 & 43.42 \\
\hline Pruritis (local) & 402 & 17.52 \\
\hline Dysparunia & 358 & 15.63 \\
\hline Dysmenorrhoea & 358 & 15.63 \\
\hline Polymenorrhagea & 321 & 13.99 \\
\hline Dysuria / Burning micturition & 102 & 4.44 \\
\hline Post coital bleeding & 26 & 1.13 \\
\hline Anorectal discharge & 11 & 0.44 \\
\hline
\end{tabular}

Table 4: Distribution according to Diagnosis $($ Total $=2294 / 100 \%)$

\begin{tabular}{|l|l|l|}
\hline Diagnosis & Number & \%age \\
\hline Vaginitis & 1434 & 62.51 \\
\hline Chronic Cervicitis & 638 & 27.81 \\
\hline Chronic Pelvic Inflammatory Disease & 358 & 15.63 \\
\hline Urethritis & 96 & 4.18 \\
\hline Anorectal discharge & 10 & 0.44 \\
\hline Syphilis & 11 & 0.48 \\
\hline Herpes simplex & 4 & 0.17 \\
\hline Condyloma accuminata & 4 & 0.17 \\
\hline
\end{tabular}

Table 5: Causative organism in Vaginal Discharge $($ Total $=1434 / 100 \%)$

\begin{tabular}{|l|l|l|l|}
\hline Types of Vaginal discharge & Causative organism & Number & \%age \\
\hline Bacterial vaginosis & Gardenella vaginalis & 713 & 49.79 \\
\hline Candidiasis & Candida albicans & 514 & 35.84 \\
\hline Trichomoniasis & Trichomonal vaginalis & 306 & 21.33 \\
\hline Bacterial & N. gonorrhoea & 84 & 13.27 \\
\hline
\end{tabular}

Table 6: Papsmear Analysis $($ Total $=996 / 100 \%)$

\begin{tabular}{|l|l|l|}
\hline & N & \%age \\
\hline Normal & 618 & 62.04 \\
\hline Inflammatory & 363 & 36.4 \\
\hline Dysplasia & 09 & 09 \\
Mild & & \\
Moderate & 3 & 0.3 \\
Severe & 4 & 0.4 \\
Koilocytosis & 2 & 0.2 \\
\hline
\end{tabular}

